\title{
Score based assessment of implant-related post fusion MRI artifacts focused on different interbody disc spacers: An in vitro study
}

\author{
Thorsten Ernstberger $^{1^{*}}$, Gabert Heidrich ${ }^{2}$, Hans-Michael Klinger ${ }^{3}$, Mike Herbert Baums ${ }^{4}$ \\ ${ }^{1}$ Clinic for Spinal Surgery, Klinikum Bad Bramstedt, Bad Bramstedt, Germany \\ ${ }^{2}$ Center of Radiology Weilheim, Ambulatory Healthcare Center, Weilheim, Germany \\ ${ }^{3}$ Department of Orthopaedic Surgery, University of Gottingen, Gottingen, Germany \\ ${ }^{4}$ Department of Orthopaedic Surgery Friedrichsheim, University of Frankfurt, Frankfurt, Germany \\ Email: ${ }^{*}$.ernstberger@klinikumbb.de
}

Received 25 February 2012; revised 23 March 2012; accepted 5 April 2012

\begin{abstract}
Interbody disc spacers for anterior spine fusion are made of different materials, such as titanium alloys or carbon fiber reinforced polymers (CFRP). Implantrelated susceptibility artifacts can decrease the quality of MRI scans. This cadaveric study aimed to demonstrate the extent that implant-related MRI artifacting affects the post fusion differentiation of the spinal canal (SC) and intervertebral disc space (IDS). In 6 cadaveric porcine spines, we evaluated the post-implantation MRI scans of a titanium and CFRP spacer that differed in shape and surface qualities. A spacer made of human cortical bone was used as a control. A defined evaluation unit was divided into regions of interest (ROI) to characterize the SC and IDS. Considering 15 different MRI sequences read independently by an interobserver-validated team of specialists artifact-affected image quality of the median MRI slice was rated on a modified score of 0-1-2-3. A maximum score of 15 points for the SC and 9 points for the IDS $(100 \%)$ was possible. Turbo spin echo sequences produced the best scores for both spacers and the control. Only the control achieved a score of $100 \%$. For the IDS the titanium and CFRP spacer maximally scored $0 \%$ and $74 \%$, for the SC $80 \%$ and $99 \%$, respectively. By using favored T1 TSE sequences the CFRP-spacer represented clear advantages in post fusion spinal imaging. Independent of artifact dimensions the used scoring system allowed us to create an implant-related ranking of MRI scan quality in reference to the bone control.
\end{abstract}

Keywords: Interbody Disc Spacer; Post Fusion MRI; Imaging Artifacts; Artifact Score

${ }^{*}$ Corresponding author.

\section{INTRODUCTION}

In the preoperative diagnostics of spinal diseases, magnetic resonance imaging (MRI) is used as a standard procedure that can visualize disc pathologies and neurological changes of the spinal canal with high precision. When anterior spine fusion proves indicated, implantation of intervertebral spacers often represents the treatment of choice. When postoperative complications arise secondary to vertebra fusion, MRI scans are frequently necessary to evaluate implant position and demonstrate any clinically relevant abnormalities to direct further surgical decisionmaking [1].

In general, the difficulties encountered with the detectability of implants in MRI studies are based on the different magnetizability of various structures resulting from local magnetic field gradients in implant-bordering regions. In these regions, spins with different frequencies predominate and lead to signal losses and image distortion [2-4]. This problem is of particular importance when the diagnostic aim is to assess implant positioning, implant shape and the implant-bone interface.

Depending on the problem to be clarified, consideration must be given to whether the MRI sequence selected will ensure the most artifact-free visualization and enable proper evaluation of implant positioning and/or pathological processes like tumorous growth or infection. Recent studies have shown that artifacting, particularly caused by metallic implants, can also be minimized through modification of routine MRI sequences [5]. This cadaveric study was conducted to determine the extent to which implant-related MRI artifacting affects the evaluation of the intervertebral disc space (IDS) as well as the spinal canal (SC). A modified scoring system (0-1-2-3) [6] was used to rank the artifacting produced by different intervertebral spacer designs compared with a human cortical bone control. Scans taken with 15 different MRI sequences 
were read independently by an interobserver-validated team of specialists who ranked image quality of the implant, paying special attention to the intervertebral disc space and the spinal canal. The scores are presented in tables and possible implant-related factors discussed.

\section{MATERIAL AND METHODS}

In this study, we performed MRI on implanted intervertebral spacers that differed in shape, material, surface quailties and implantation technique. 6 spinal columns of domestic pigs killed for commercial human consumption purchased from a slaughterhouse served as our experimental in vitro model. 2 spacers were implanted in the distal third of the thoracic spine and the entire lumbar spine. Additionally, a piece of human cortical bone was implanted as a control (Figures 1(a)-(c)).

\subsection{Spacers}

The Union carbon cage (UCC) (Figure 1(a)), manufactured by Medtronic Sofamor Danek, Inc., Memphis, Tennessee, is made of a carbon fiber-reinforced polymer. The implant used in this study had an edge length of $24 \times$ $26 \mathrm{~mm}$, a height of $10 \mathrm{~mm}$ and a 7-degree taper from the proximal to the distal. The walls and midsection were 2 mm thick. The upper and lower faces exhibited three anchorage struts. The UCC is designed with two chambers for impacting cancellous bone.

The Intervertebral Body Spacer (IBS) (Figure 1(b)), manufactured by Peter Brehm GmbH, Chirurgie Mechanik, Weisendorf, Germany, is made of a titanium aluminum vanadium alloy. This square implant has an evenly ribbed structure on its upper and lower faces and an edge length of $25 \times 25 \mathrm{~mm}$. The implant used in this study had a maximum height of $10 \mathrm{~mm}$ in the anterior segment with a dorsal inclination of 7 degrees.

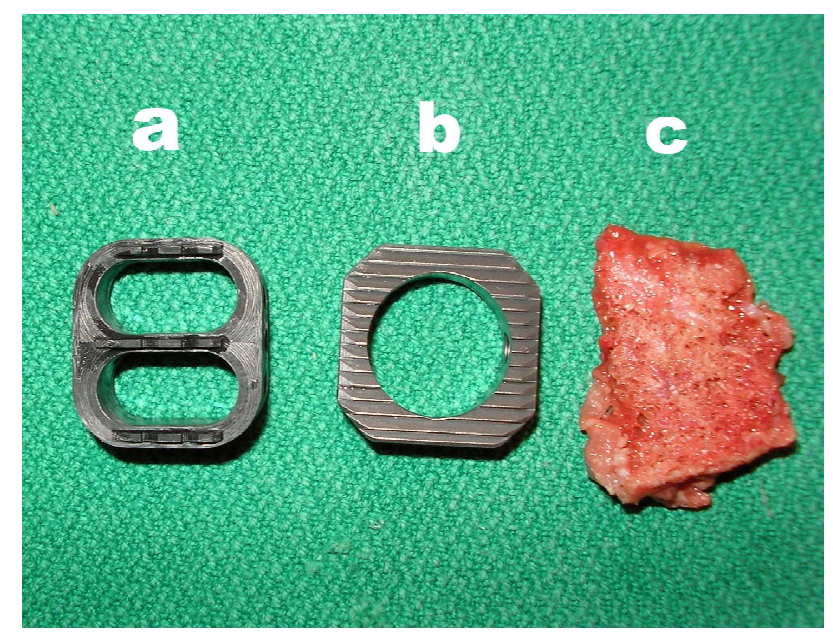

Figure 1. (a) Union-cage (carbon fiber reinforced polymers); (b) IBS-spacer (titan-aluminium-vanadium); (c) Control.

\subsection{Implantation}

Like in the human spine, the size of the vertebrae in the porcine spine increases in the craniocaudal direction, with the lower lumbar vertebrae extending to the maximum dimensions of $25 \mathrm{~mm}$ in height, $25 \mathrm{~mm}$ in width and 20 $\mathrm{mm}$ in depth. The dimensions of the 2 study spacers and the control were selected to be oversized compared to the intervertebral disc space. The 2 devices were implanted as stand-alone cages. We refrained from the use of dorsally implanted pedicle screws so as to avoid any potential summation effects on artifact scoring caused by additional materials.

A purely spinal model was chosen instead of a whole pig cadaver, since the size of the clinical field of view routinely focuses on the spine and cuts out any thoracic or abdominal organ structures. During dissection, the paravertebral muscles including the surrounding skin and the psoas muscles of the spine were retained.

To avoid artifact overlapping of spacers a minimum implant distance of two vertebral bodies were determined.

Accordingly, the intervertebral disc spacers were dissected to achieve a median positioning of the implants. The paravertebral muscles were left intact along with the skin and psoas muscles. Maximum implantation depth was reached when the implant was aligned with the anterior vertebra face. After implantation was completed, additional tissue mass was padded around the spine to optimize contrast and image quality. A conventional radiograph was then taken for documentation purposes (Figures 2(a)-(c)).

\subsection{Magnetic Resonance Imaging}

MRI was performed with a 1.5T MRI (Magnetom Symphony, Siemens AG Medical Solutions, Erlangen, Germany). Table 1 presents the MRI data. The median sagittal MRI slice encompassing all relevant structures, implants and control was evaluated according to a modified interobserver-validated scoring system.

\subsection{Scoring System}

A modified 0-1-2-3 scoring system [6] was established to

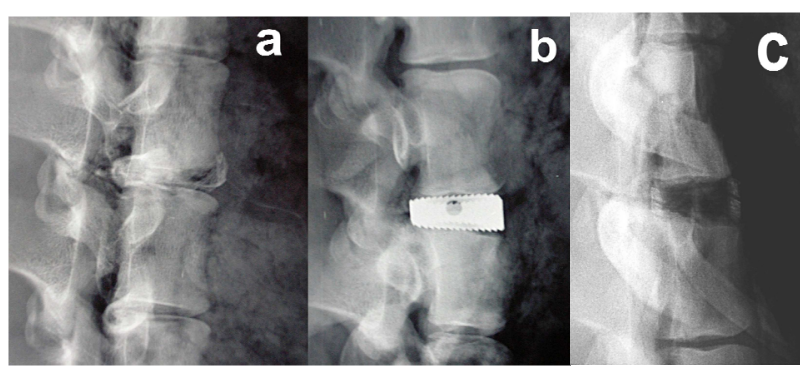

Figure 2. Lateral radiographs: (a) Control; (b) IBS-spacer; (c) Union-cage. 
Table 1. MRI sequence data.

\begin{tabular}{ccccccccc}
\hline Sequences & FA & TR & TE & ST & BW & FOV & Number of slices & Matrix \\
\hline T1 FLASH 2D & 70 & 181 & 4.8 & 5.5 & 260 & 500 & 19 & $256 \times 256$ \\
T1 FLASH 2D FS & 70 & 275 & 4.76 & 5.5 & 260 & 500 & 19 & $256 \times 256$ \\
T2 MEDIC 2D FS & 40 & 2660 & 27 & 3.0 & 70 & 500 & 40 & $256 \times 256$ \\
T1 FLASH 3D & 60 & 60 & 11 & 3.0 & 70 & 500 & 40 & $256 \times 256$ \\
T2 DESS 3D & 25 & 23.68 & 6.63 & 1.5 & 130 & 500 & 64 & $256 \times 256$ \\
TOF FISP 3D & 25 & 36 & 4.59 & 3.0 & 130 & 500 & 32 & $384 \times 384$ \\
T2 CISS 3D & 70 & 10.16 & 5.08 & 3.0 & 130 & 500 & 64 & $256 \times 256$ \\
T1 TSE & 150 & 2260 & 14 & 3.0 & 150 & 500 & 40 & $512 \times 512$ \\
T1 TSE var & 150 & 600 & 14 & 3.0 & 150 & 500 & 40 & $512 \times 512$ \\
T1 SE & 90 & 1270 & 14 & 3.0 & 90 & 500 & 40 & $512 \times 512$ \\
T1 SE var & 90 & 600 & 14 & 3.0 & 90 & 500 & 40 & $512 \times 512$ \\
T1 SE FS var & 90 & 684 & 14 & 3.0 & 90 & 500 & 40 & $512 \times 512$ \\
T2 TSE/PD & 150 & 6110 & 14 & 3.0 & 130 & 500 & 40 & $256 \times 256$ \\
T2 TSE/PD FS & 150 & 6760 & 14 & 3.0 & 130 & 500 & 40 & $256 \times 256$ \\
STIR & 180 & 10,000 & 38 & 3.0 & 130 & 500 & 40 & $256 \times 256$ \\
\hline
\end{tabular}

Key: FLASH = Fast Low Angle Shot; MEDIC = Multi Echo Data Image Combination; DESS = Dual Echo Steady State; FS = Fat Saturated; FISP = Fast Imaging with Steady Precession; CISS = Constructive Interference in Steady State; SE = Spin Echo; TSE = Turbo Spin Echo; PD = Proton Density; STIR = Short Tau Inversion Recovery; TOF = Time of Flight; TR = Time of Repetition; TE = Time of Echo; FA = Flip Angle; ST = Slab Thickness; BW = Band Width; FOV = Field of View; var = Varied.

rank the MRI scans. An evaluation unit was defined as 2 adjacent vertebrae encompassing the intervertebral disc space. Regions of interest (ROI) were demarcated to characterize the intervertebral disc space and the spinal canal (Figures 3(a) and (b)). Every ROI could achieve a maximum score of 3 points. A total score of 9 points for the IDS and 15 points for the SC was equivalent to a score of $100 \%$. Two board-certified specialists (one spinal surgeon and one radiologist and)) experienced in reading spinal MRI evaluated the scans independently of each other. The evaluators scored regions as $0=$ not distinguishable, 1 = partly distinguishable (less than 50\%), 2 $=$ partly distinguishable (more than $50 \%$ ) and $3=$ completely distinguishable. The interobserver validation of the scoring system for MRI sequences with the best imaging scores was tested for statistical significance using a $t$ test with a significance level of $\alpha=0.05$.

\section{RESULTS}

Considering all 15 MRI sequences of our study protocol the results showed that both used T1-TSE sequences produced the best imaging scores for all implants. In these sequences, the human cortical bone control achieved the maximum possible score of $100 \%$, i.e. was completely distinguishable (Figure 4(a)). Therefore, we used these two sequences as a basis for following comparison of the imaging quality of the study implants. Figure 4 depicts the artifact range in a selection of 4 MRI sequences.

\subsection{IBS}

In the T1-TSE sequences, the titanium IBS implant achieved an imaging score of $0 \%$ for the intervertebral disc space and approximately $80 \%$ for the spinal canal

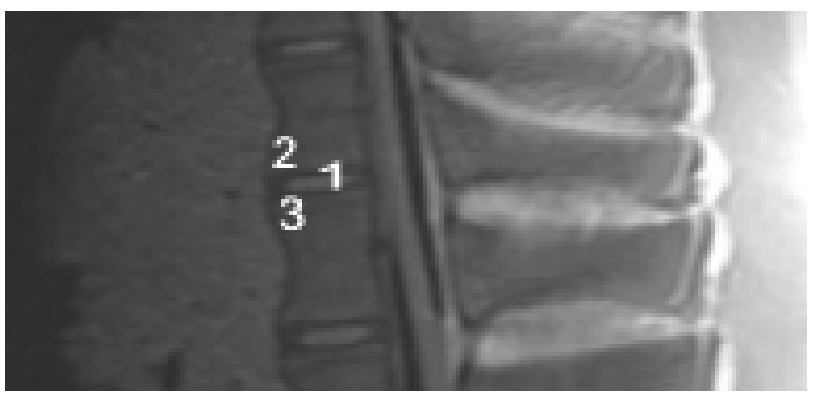

(a)

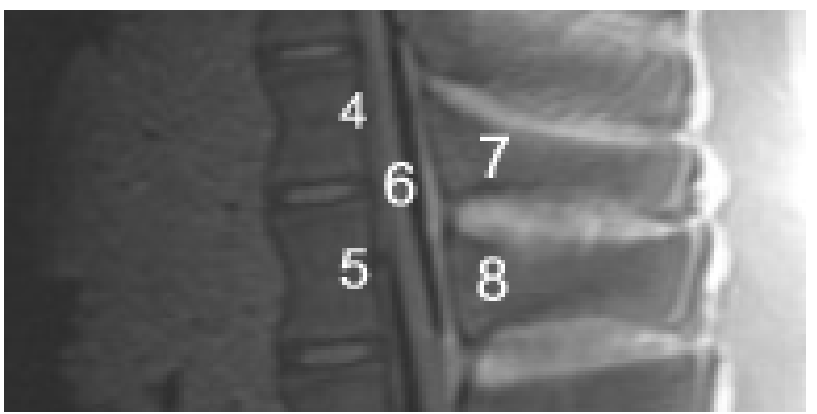

(b)

Figure 3. (a) MRI-Evaluation unit with Regions of interest (ROI): 1) Intervertebral disc space; 2) Superior end plate; 3) Inferior end plate; (b) MRI-evaluation unit with regions of interest (ROI): 4) Posterior edge of the cranial vertebra; 5) Posterior edge of the cranial vertebra; 6) Spinal canal; 7) Cranial spinous process; 8) Caudal spinous process.

compared to the control (Tables 2(a)-(d)). The susceptibility artifact border was clearly distinguishable from its surroundings. As a result of artifact extension, the implant-bone contact area was not distinguishable. The image quality was not sufficient to determine exact implant position and implant shape. 


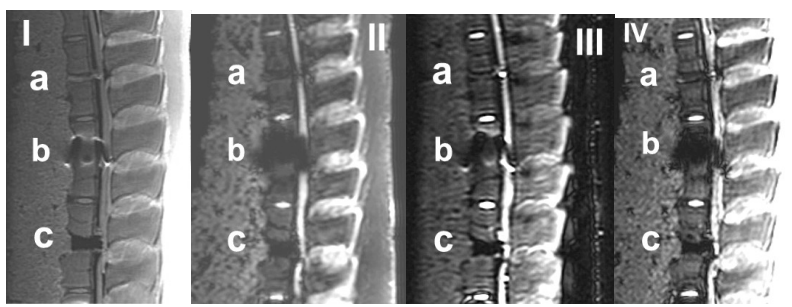

Figure 4. I-IV: Artifact range depicted in a selection of MRI sequences: a) Control; b) IBS-spacer; c) Union-cage; I: T1 TSE (TR: 2260, TE: 14); II: T2 DESS 3D (TR: 23, TE: 6); III: STIR (TR: 10000, TE: 38); IV: T2 CISS 3D (TR: 10, TE: 5).

Table 2. (a) MRI-evaluation ROI (4-8); Spinal surgeon; (b) MRI-evaluation ROI (4-8); Radiologist; (c) MRI-evaluation ROI (1-3); Spinal surgeon; (d) MRI-evaluation ROI (1-3); Radiologist.

(a)

\begin{tabular}{|c|c|c|c|}
\hline $\begin{array}{c}\text { MRI-sequence: T1 } \\
\text { TSE } \\
\text { (TR: 600, TE: } 14 \text { ) }\end{array}$ & $\begin{array}{l}\text { Union-carbon- } \\
\text { cage }\end{array}$ & $\begin{array}{l}\text { IBS-titanium- } \\
\text { cage }\end{array}$ & Control \\
\hline \multicolumn{4}{|l|}{$\begin{array}{l}\text { Series of tests I-VI } \\
\text { [ROI 4-8] }\end{array}$} \\
\hline $\begin{array}{l}\text { Mean score } \\
\text { ( } \pm \text { standard } \\
\text { deviation) }\end{array}$ & $6.33( \pm 1.96)$ & $0( \pm 0)$ & $9( \pm 0)$ \\
\hline $\begin{array}{l}\text { MRI-detectability } \\
\text { (percentage) }\end{array}$ & $\sim 70 \%$ & $0 \%$ & $100 \%$ \\
\hline $\begin{array}{c}\text { MRI-sequence: T1 } \\
\text { TSE } \\
\text { (TR: 2260, TE: } 14 \text { ) }\end{array}$ & $\begin{array}{l}\text { Union-carbon- } \\
\text { cage }\end{array}$ & $\begin{array}{l}\text { IBS-titanium- } \\
\text { cage }\end{array}$ & Control \\
\hline \multicolumn{4}{|l|}{$\begin{array}{l}\text { Series of tests I-VI } \\
\text { [ROI 4-8] }\end{array}$} \\
\hline $\begin{array}{l}\text { Mean score } \\
\text { ( } \pm \text { standard } \\
\text { deviation) }\end{array}$ & $6.37( \pm 1.37)$ & $0( \pm 0)$ & $9( \pm 0)$ \\
\hline $\begin{array}{l}\text { MRI-detectability } \\
\text { (percentage) }\end{array}$ & 70\% & $0 \%$ & $100 \%$ \\
\hline
\end{tabular}

(b)

\begin{tabular}{|c|c|c|c|}
\hline $\begin{array}{l}\text { MRI-sequence: T1 } \\
\text { TSE } \\
\text { (TR: 600, TE: } 14 \text { ) }\end{array}$ & $\begin{array}{l}\text { Union-carbon- } \\
\text { cage }\end{array}$ & $\begin{array}{l}\text { IBS-titanium- } \\
\text { cage }\end{array}$ & Control \\
\hline \multicolumn{4}{|l|}{$\begin{array}{l}\text { Series of tests I-VI } \\
\text { [ROI 4-8] }\end{array}$} \\
\hline $\begin{array}{l}\text { Mean score } \\
\text { ( } \pm \text { standard } \\
\text { deviation) }\end{array}$ & $6.33( \pm 1.97)$ & $0( \pm 0)$ & $9( \pm 0)$ \\
\hline $\begin{array}{l}\text { MRI-detectability } \\
\text { (percentage) }\end{array}$ & 70\% & $0 \%$ & $100 \%$ \\
\hline $\begin{array}{c}\text { MRI-sequence: T1 } \\
\text { TSE } \\
\text { (TR: 2260, TE: 14) }\end{array}$ & $\begin{array}{l}\text { Union-carbon- } \\
\text { cage }\end{array}$ & $\begin{array}{l}\text { IBS-titanium- } \\
\text { cage }\end{array}$ & Control \\
\hline \multicolumn{4}{|l|}{$\begin{array}{l}\text { Series of tests I-VI } \\
\text { [ROI 4-8] }\end{array}$} \\
\hline $\begin{array}{l}\text { Mean score } \\
\text { ( } \pm \text { standard } \\
\text { deviation) }\end{array}$ & $6.33( \pm 1.97)$ & $0( \pm 0)$ & $9( \pm 0)$ \\
\hline $\begin{array}{l}\text { MRI-detectability } \\
\text { (percentage) }\end{array}$ & 70\% & $0 \%$ & $100 \%$ \\
\hline
\end{tabular}

(c)

\begin{tabular}{|c|c|c|c|}
\hline $\begin{array}{c}\text { MRI-sequence: T1 } \\
\text { TSE } \\
\text { (TR: 600, TE: } 14 \text { ) }\end{array}$ & $\begin{array}{l}\text { Union-carbon- } \\
\text { cage }\end{array}$ & $\begin{array}{l}\text { IBS-titanium- } \\
\text { cage }\end{array}$ & Contro \\
\hline \multicolumn{4}{|l|}{$\begin{array}{c}\text { Series of tests I-VI } \\
\text { [ROI 1-3] }\end{array}$} \\
\hline $\begin{array}{l}\text { Mean score } \\
\text { ( } \pm \text { standard } \\
\text { deviation) }\end{array}$ & $14.67( \pm 0.52)$ & $11.83( \pm 0.41)$ & $15( \pm 0)$ \\
\hline $\begin{array}{l}\text { MRI-detectability } \\
\text { (percentage) }\end{array}$ & $\sim 98 \%$ & $80 \%$ & $100 \%$ \\
\hline $\begin{array}{c}\text { MRI-sequence: T1 } \\
\text { TSE } \\
\text { (TR: 2260, TE: } 14 \text { ) }\end{array}$ & $\begin{array}{l}\text { Union-carbon- } \\
\text { cage }\end{array}$ & $\begin{array}{l}\text { IBS-titanium- } \\
\text { cage }\end{array}$ & Contro \\
\hline \multicolumn{4}{|l|}{$\begin{array}{c}\text { Series of tests I-VI } \\
\text { [ROI 1-3] }\end{array}$} \\
\hline $\begin{array}{l}\text { Mean score } \\
\text { ( } \pm \text { standard } \\
\text { deviation) }\end{array}$ & $14.83( \pm 0.41)$ & $12.0( \pm 0)$ & $15( \pm 0)$ \\
\hline $\begin{array}{l}\text { MRI-detectability } \\
\text { (percentage) }\end{array}$ & $\sim 99 \%$ & $79 \%$ & $100 \%$ \\
\hline \multicolumn{4}{|c|}{ (d) } \\
\hline $\begin{array}{c}\text { MRI-sequence: T1 } \\
\text { TSE } \\
\text { (TR: 600, TE: 14) }\end{array}$ & $\begin{array}{l}\text { Union-carbon- } \\
\text { cage }\end{array}$ & $\begin{array}{l}\text { IBS-titanium- } \\
\text { cage }\end{array}$ & Contro \\
\hline \multicolumn{4}{|l|}{$\begin{array}{l}\text { Series of tests I-VI } \\
\text { [ROI 1-3] }\end{array}$} \\
\hline $\begin{array}{l}\text { Mean score } \\
\text { ( } \pm \text { standard } \\
\text { deviation) }\end{array}$ & $14.5( \pm 0.55)$ & $11.83( \pm 0.41)$ & $15( \pm 0)$ \\
\hline $\begin{array}{l}\text { MRI-detectability } \\
\text { (percentage) }\end{array}$ & $\sim 97 \%$ & $80 \%$ & $100 \%$ \\
\hline $\begin{array}{c}\text { MRI-sequence: T1 } \\
\text { TSE } \\
\text { (TR: 2260, TE: } 14 \text { ) }\end{array}$ & $\begin{array}{l}\text { Union-carbon- } \\
\text { cage }\end{array}$ & $\begin{array}{l}\text { IBS-titanium- } \\
\text { cage }\end{array}$ & Contro \\
\hline \multicolumn{4}{|l|}{$\begin{array}{c}\text { Series of tests I-VI } \\
\text { [ROI 1-3] }\end{array}$} \\
\hline $\begin{array}{l}\text { Mean score } \\
\text { ( } \pm \text { standard } \\
\text { deviation) }\end{array}$ & $14.67( \pm 0.52)$ & $12.0( \pm 0)$ & $15( \pm 0)$ \\
\hline $\begin{array}{l}\text { MRI-detectability } \\
\text { (percentage) }\end{array}$ & $\sim 98 \%$ & $79 \%$ & $100 \%$ \\
\hline
\end{tabular}

\subsection{UCC}

In the T1-TSE sequences, the UCC achieved an image quality comparable to the control (Figure 4 (c)). Susceptibility artifacts formed a sharp border with the vertebral surroundings. Compared to the IBS-spacer, the implantbone contact area achieved an imaging score up to 79\% (Tables 2(a) and (b)) in comparison to the control. With an maximum imaging score of 99\% (Tables 2(c) and (d)) unequivocal differentiation between spinal canal and implant position was possible.

\subsection{Interobserver Validation}

The results of the interobserver validation are listed in Tables 3 and 4. There was no statistical significance between the evaluators with respect to t-test correlations (P $>0.05)$. 
Table 3. (a), (b) Interobserver correlation ROI 1-3 (spinal surgeon/radiologist).

(a)

\begin{tabular}{|c|c|c|c|}
\hline $\begin{array}{c}\text { MRI-sequence: } \\
\text { T1 TSE } \\
\text { (TR: 600, TE: 14) } \\
\text { ROI 1-3 }\end{array}$ & P-value & $\begin{array}{c}\text { Mean } \\
\text { (difference) }\end{array}$ & $\begin{array}{l}\text { Standard deviation } \\
\text { (difference) }\end{array}$ \\
\hline Union-cage & 1.0 & 0.0 & 1.07 \\
\hline IBS-spacer & \multicolumn{3}{|c|}{ No variance within groups } \\
\hline \multicolumn{4}{|c|}{ (b) } \\
\hline $\begin{array}{l}\text { MRI-sequence: } \\
\text { T1 TSE } \\
\text { (TR: 2260, TE: 14) } \\
\text { ROI 1-3 }\end{array}$ & P-value & $\begin{array}{c}\text { Mean } \\
\text { (difference) }\end{array}$ & $\begin{array}{l}\text { Standard deviation } \\
\text { (difference) }\end{array}$ \\
\hline Union-cage & 0.62 & 0.33 & \pm 0.65 \\
\hline IBS-spacer & \multicolumn{3}{|c|}{ No variance within groups } \\
\hline
\end{tabular}

Table 4. (a), (b) Interobserver correlation ROI 4-8 (spinal surgeon/radiologist).

(a)

\begin{tabular}{|c|c|c|c|}
\hline $\begin{array}{l}\text { MRI-sequence: } \\
\text { T1 TSE } \\
\text { (TR: 600, TE: 14) } \\
\text { ROI 4-8 }\end{array}$ & P-value & $\begin{array}{c}\text { Mean } \\
\text { (difference) }\end{array}$ & $\begin{array}{l}\text { Standard deviation } \\
\text { (difference) }\end{array}$ \\
\hline Union-cage & 0.59 & 0.17 & \pm 0.31 \\
\hline IBS-spacer & 0.26 & 0.33 & \pm 0.28 \\
\hline
\end{tabular}

(b)

\begin{tabular}{|c|c|c|c|}
\hline $\begin{array}{l}\text { MRI-sequence: } \\
\text { T1 TSE } \\
\text { (TR: 2260, TE: 14) } \\
\text { ROI 4-8 }\end{array}$ & P-value & $\begin{array}{c}\text { Mean } \\
\text { (difference) }\end{array}$ & $\begin{array}{l}\text { Standard deviation } \\
\text { (difference) }\end{array}$ \\
\hline Union-cage & 0.55 & 0.17 & \pm 0.27 \\
\hline IBS-spacer & 0.18 & 0.33 & \pm 0.21 \\
\hline
\end{tabular}

\section{DISCUSSION}

The disadvantage associated with bone grafting alone has led to the development of intervertebral spacers to enhance anterior spinal fusion [1,7-9]. The use of intervertebral spacers of different designs and materials has thus become increasingly widespread in clinical routine be- cause they offer immediate load transmission with direct primary stability. Post-fusion MRI scans are used for further diagnostics to demonstrate any progressive degenerative changes, infections, fractures and/or tumors. However, implant-related susceptibility artifacts can negatively impact the complex post-fusion evaluation of MRI scans. Depending on the spacer material, a local magnetic field gradient of varying susceptibility results in the area between structures. In these border areas, the respective spins gyrate with different frequencies and cause image distortions and susceptibility artifacts [2,3].

Optimum MRI visualization of the different intervertebral spacers depends on the aim of diagnosis. MRI diagnostics are insofar subject to different requirements depending on the various postoperative pathologies in relation to the implant situation. This was the first study to evaluate a titanium (IBS) versus carbon (UCC) intervertebral disc spacer imaged in a total of 15 different MRI sequences. Maximum MRI distinguishability of the intervertebral spacers and the equivalent control was achieved using T1 TSE sequences. The imaging quality of the human cortical bone used as a control scored $100 \%$ according to the study scoring system and was therefore used as a basis to rank the intervertebral spacers examined. The scores were stated as a percentage compared to the control. Our interobserver-validated scoring system allowed us to create a unique implant-related ranking of MRI scan quality in reference to a control that was independent of artifact dimensions. In this connection an evaluation of seperate spinal ROI could be carried out. With regard to the respective implant detectibility implant-related differences considering post fusion MR imaging quality of the spinal canal as well as the intervertebral disc space were stated additionally.

Of both intervertebral spacers we examined, the UCC scored the highest in comparison to the human bone control. This is in line with recent publications $[10,11]$ that showed that carbon produced a very low rate of artifact reactions. In this connection, the limited distinguishability of the implant-bone contact area and the intervertebral disc space was negligible. The implant position in relation to the SC was best visualized using T1 TSE sequences.

The comparatively lower scores achieved by the IBS spacer are assumed to be based on the materials' greater tendency to cause susceptibility artifacts.

The MRI imaging behavior of metallic spinal implants is well documented in the literature [4,12-18]. However, the aims of the published studies differed in that most focused on determining sequence-related artifact size.

Consistent with our results in studies by Rudisch et al. [19] Thomsen et al. [20] and Wang et al. [17], titanium materials achieved the best MRI quality with fast spin echo sequences. Other MRI sequences produced no fur- 
ther advantages (Figure 4). In our study, when T1 TSE sequences were used to image the titanium spacer, neither implant characteristics like shape and in situ position nor implant-bone interface could be distinguished with certainty. In this context only the MRI scan quality of the spinal canal were approximately comparable to the result of the examined carbon cage. In a phantom study by Rudisch et al. [20], the relevance of metallic artifacts and implant-related characteristics, such as implant material, shape and position was demonstrated in addition to an impact by the selected MRI sequence. In spite of the use of optimum MRI sequences, variability in the amount of susceptibility artifacts must be accounted for when evaluating MRI scans of spine implants.

\section{CONCLUSION}

The designs and materials of the intervertebral spacers currently used in anterior spine fusion cause susceptibility artifacts that can be rated by validated scoring systems independent from artifact dimensions. Compared with titanium-alloy, carbon ranked the highest in allowing evaluation of local implant situation and pathological processes and showed the least amount of susceptibility artifacting. Of 15 sequences tested, fast spin echo sequences produced the best spacer imaging for all examined implants. An interobserver-validated scoring system proved effective in ranking the relevance of spacer material on MRI scan quality independent from artifact dimensions.

\section{REFERENCES}

[1] Van Goethem, J.W., Parizel, P.M. and Jinkins, J.R. (2002) Review article: MRI of the postoperative lumbar spine. Neuroradiology, 44, 723-739. doi:10.1007/s00234-002-0790-2

[2] Fellner, C., Behr, M., Fellner, F., Held, P., Handel, G. and Feuerbach, S. (1997) Artifacts in MR imaging of the temporomandibular joint caused by dental alloys: A phantom model study at 1.5 T. Fortschr Röntgenstr, 166, 421-428. doi:10.1055/s-2007-1015452

[3] Fritzsche, S., Thull, R. and Haase, A. (1994) Reduction of artifacts in magnetic resonance images by using optimized materials for diagnostic devices and implants. Biomedizinische Technik, Berlin, 39, 42-46. doi:10.1515/bmte.1994.39.3.42

[4] Ortiz, O., Pait, T.G., McAllister, P. and Sauter, K. (1996) Postoperative MRI with titanium implants of the thoracic and lumbar spine. Neurosurgery, 38, 741-745. doi:10.1227/00006123-199604000-00022

[5] Herold, T., Caro, W.C., Heers, G., Perlick, L., Grifka, J., Feuerbach, S., Nitz, W. and Lenhart, M. (2004) Influence of sequence type on the extent of the susceptibility artifact in MRI: A shoulder specimen study after suture anchor repair. Fortschr Röntgenstr, 176, 1296-1301. doi:10.1055/s-2004-813404
[6] Ernstberger, T., Heidrich, G., Bruening, T., Krefft, S., Buchhorn, G. and Klinger, H.M. (2007) The interobserver-validated relevance of intervertebral spacer materials in MRI artifacting. European Spine Journal, 16, 179-185. doi:10.1007/s00586-006-0064-5

[7] Brantigan, J.W. and Steffee, A.D. (1993) A carbon fiber implant to aid interbody lumbar fusion. Two-year clinical results in the first 26 patients. Spine, 18, 2106-2107. doi:10.1097/00007632-199310001-00030

[8] Goulet, J.A., Senunas, L.E., De Silva, G.L. and Greenfield, M.L. (1997) Autogenous iliac crest bone graft. Complications and functional assessment. Clinical Orthopaedics, 339, 76-81. doi:10.1097/00003086-199706000-00011

[9] Summers, B.N. and Eisenstein, S.M. (1989) Donor site pain from the ilium. A complication of lumbar spine fusion. Journal of Bone and Joint Surgery British Volume, 71, 677-680.

[10] Bader, R., Steinhauser, E., Rechl, H., Siebels, W., Mittelmeier, W. and Gradinger, R. (2003) Carbon fiber-reinforced plastics as implant materials. Der Orthopade, 32, 32-40. doi:10.1007/s00132-002-0410-1

[11] Weiner, B.K. and Fraser, R.D. (1998) Spine update lumbar interbody cages. Spine, 23, 634-640. doi:10.1097/00007632-199803010-00020

[12] Henk, C.B., Brodner, W., Grampp, S., Breitenseher, M., Thurnher, M., Mostbeck, G.H. and Imhof, H. (1999) The postoperative spine. Topics Magnetic Resonance Imaging, 10, 247-264. doi:10.1097/00002142-199908000-00006

[13] Malik, A.S., Boyko, O., Atkar, N. and Young, W.F. (2001) A comparative study of MR imaging profile of titanium pedicle screws. Acta Radiologica, 42, 291-293. doi:10.1080/028418501127346846

[14] Petersilge, C.A., Lewin, J.S., Duerk, J.L., Yoo, J.U. and Ghaneyem, A.J. (1996) Optimizing imaging parameters for MR evaluation of the spine with titanium pedicle screws. American Journal of Roentenology, 166, 12131218.

[15] Rupp, R., Ebraheim, N.A., Savolaine, E.R. and Jackson, W.T. (1993) Magnetic resonance imaging evaluation of the spine with metal implants. General safety and superior imaging with titanium. Spine, 18, 379-385. doi:10.1097/00007632-199303000-00014

[16] Wang, J.C., Sandhu, H.S., Yu, M.D., Minchew, J.T. and Delamarter, R.B. (1997) MR parameters for imaging titanium spinal instrumentation. Journal of Spinal Disorders, 10, 27-32. doi:10.1097/00002517-199702000-00004

[17] Wang, J.C., Yu, W.D., Sandhu, H.S., Tam, V. and Delamarter, R.B. (1998) A comparison of magnetic resonance and computed tomographic image quality after the implantation of tantalum and titanium spinal instrumentation. Spine, 23, 1684-1688. doi:10.1097/00007632-199808010-00014

[18] Vaccaro, A.R., Chesnut, R.M., Scuderi, G., Healy, J.F., Massie, J.B. and Garfin, S.R. (1994) Metallic spinal artifacts in magnetic resonance imaging. Spine, 19, $1237-$ 1242.

[19] Rudisch, A., Kremser, C., Peer, S., Kathrein, A., Judmaier W. and Daniaux, H. (1998) Metallic artifacts in magnetic resonance imaging of patients with spinal fusion: A 
comparison of implant materials and implant sequences.

Spine, 23, 692-699.

doi:10.1097/00007632-199803150-00009

[20] Thomsen, M., Schneider, U., Breusch, S.J., Hansmann, J. and Freund, M. (2001) Artefacts and ferromagnetism dependent on different metal alloys in magnetic resonance imaging. An experimental study. Der Orthopade, 30, 540-544. doi:10.1007/s001320170063 